Check for updates

Cite this: RSC Adv., 2019, 9, 1747

Received 15th November 2018

Accepted 8th January 2019

DOI: $10.1039 / \mathrm{c} 8 \mathrm{ra09419e}$

rsc.li/rsc-advances

\title{
Near-infrared emitting lanthanide(III) complexes as prototypes of optical imaging agents with peptide targeting ability: a methodological approach $\uparrow$
}

\author{
Monika Cieslikiewicz-Bouet, (DD ${ }^{a}$ Svetlana V. Eliseeva, (D) ${ }^{\mathrm{b}}$ Vincent Aucagne, (D) ${ }^{\mathrm{b}}$ \\ Agnès F. Delmas, ${ }^{b}$ Isabelle Gillaizeau (D) *a and Stéphane Petoud (D) *b
}

A methodological approach to design prototypes of specific near-infrared emitting imaging agents based on a small molecular compound combining a lanthanide(III) ion, the cyclen derivative as a coordinating unit and the azo-dye as a sensitizer with a Arg-Gly-Asp cyclopeptide as a targeting moiety, is presented here.

Optical molecular imaging is in ever-increasing demand for biological research and medical diagnosis as it provides a high detection sensitivity using relatively inexpensive equipment for acquisition and maintenance that can be easily moved to the experiment site. The main requirement to benefit from these advantages is the availability of fluorescent or luminescent imaging agents. Detection in the near-infrared (NIR) range is currently triggering strong enthusiasm for in vitro and in vivo applications as measurements performed in this spectral domain minimize the contribution of the native fluorescence of biological systems (autofluorescence), providing a higher signal-to-noise ratio and correspondingly enhanced detection sensitivity. ${ }^{1}$ In this respect, the luminescence of lanthanide(III) ions $\left(\mathrm{Ln}^{3+}\right)$ possesses complementary advantages in respect to organic fluorophores and semi-conductor nanocrystals (quantum dots): sharp emission bands whose wavelengths are not affected by the experimental conditions, large energy differences between excitation and emission bands (pseudoStokes shift), and long luminescence lifetimes ( $\mu \mathrm{s}-\mathrm{ms}$ range). ${ }^{2}$ However, the forbidden nature of most of the $\mathrm{f}-\mathrm{f}$ transitions results in the extremely low absorption of free $\mathrm{Ln}^{3+}$, strongly limiting the number of photons emitted. In order to overcome this limitation, $\mathrm{Ln}^{3+}$ need to be located sufficiently close to a chromophoric ligand able to absorb a high number of photons and to transfer the resulting energy to the $\mathrm{Ln}^{3+}$. This sensitization mechanism is called "the antenna effect". ${ }^{3}$ In our quest for the creation of NIR-emitting imaging agents based on Ln(III) compounds, we have tested several approaches and

\footnotetext{
'Institut de Chimie Organique et Analytique, UMR CNRS 7311, Université d'Orléans, rue de Chartres, 45100 Orléans, France. E-mail: isabelle.gillaizeau@univ-orleans.fr ${ }^{b}$ Centre de Biophysique Moléculaire, CNRS UPR 4301, rue Charles Sadron, 45071 Orléans Cedex 2, France. E-mail: stephane.petoud@inserm.fr

$\dagger$ Electronic supplementary information (ESI) available: Experimental procedures, characterization data, NMR spectra and details of photophysical measurements. See DOI: $10.1039 / \mathrm{c} 8 \mathrm{ra09419e}$
}

systems that have shown their ability to be used under biological conditions as cell imaging probes. ${ }^{4}$ However, some of these systems have relatively large sizes (i.e. metal-organic frameworks ${ }^{4 a}$ and dendrimers ${ }^{4 b}$ ) with the potential risk of interfering with the biological systems to be studied. Moreover, none of the NIR-emitting Ln(III)-based imaging probes that we have created so far possess the capability of being functionalized with a biological recognition entity in order to target a specific location. ${ }^{4 c, d}$ The goal of the present project was therefore to create prototypes of Ln(III)-based NIR-emitting agents based on small molecules using a methodological design approach that allows the attachment of a targeting peptide to a chromophoric unit. In addition, these prototypes have also to include $\operatorname{Ln}(\mathrm{III})$ complexes: for $\operatorname{Ln}($ III) complexes to be used as imaging agents, two essential parameters are a high thermodynamic stability and/or kinetic inertness as these properties reflect the absence of dissociation and therefore prevent the loss of the luminescence signal and the release of free $\mathrm{Ln}^{3+}$ that are toxic during experiments. A derivative of the 1,4,7,10-tetraazacyclodecane1,4,7-triacetic acid (DO3A) macrocycle was chosen to coordinate $\mathrm{Ln}^{3+}$ due to the almost complete absence of dissociation of the corresponding complexes in aqueous media $\left(\log K_{\mathrm{LnL}}\right.$ up to 29). ${ }^{5}$ Among functional fluorophores, azo-dyes are a wellestablished class of organic photoactive molecules that possess excellent chemical stability, and have been widely used as photoswitches to follow changes in different biological systems. ${ }^{6}$ They can tolerate a broad range of organic reactions, an ideal feature to successively install the $\mathrm{Ln}^{3+}$ complex and the targeting moiety. Only few reports described the use of azo-dyes as sensitizers of NIR-emitting $\mathrm{Ln}^{3+}$ ions. ${ }^{6 d, e}$ Furthermore, molecules based on azo-dyes can be chemoselectively conjugated to any biomolecule able to target a specific receptor for biological imaging applications. Here, we used this specificity through the copper-catalyzed alkyne/azide cycloaddition ${ }^{7}$ (CuAAC) conjugation with a cyclopeptide containing an Arg-Gly- 
Asp (RGD) moiety. This tripeptide motif is a ligand of the $\alpha_{v} \beta_{3}$ integrin overexpression which is associated with the progression of various processes such as osteoclast mediated bone resorption, angiogenesis and pathological neovascularisation, as well as tumour metastasis. ${ }^{\mathbf{8}}$ Among many RGD-containing molecules, the cyclo(Arg-Gly-Asp-D-Phe-Val) peptide (cRGD) initially developed by Kessler and co-workers for cancer therapy ${ }^{9}$ is a highly potent and selective $\alpha_{v} \beta_{3}$ antagonist. This breakthrough discovery paved the way for the development of cRGD derivatives conjugated with cytotoxic compounds or probes for applications in targeted drug delivery or cancer imaging, respectively. ${ }^{10}$ This cyclopentapeptide targeting unit is now widely established, and we used it as a benchmark to demonstrate the validity and versatility of our synthetic strategy.

Cyclen-based ligands incorporating azo-dyes for the binding and sensitization of NIR-emitting $\mathrm{Ln}^{3+}$ ions were prepared following the procedure presented on Scheme 1. To pursue our objective of developing new nitrogen containing compounds, ${ }^{11}$ azobenzene compounds $\mathbf{3 a - d}$ were synthesized using standard conditions from aniline derivatives 1a-d. The versatility of this synthetic strategy was validated since the reaction was successfully performed using aniline derivatives with different para-substituents including the electron-donating methoxy group that provides solubility or a halogen atom that allows further cross-coupling reactions to be performed. ${ }^{12}$ With the aim of introducing a biomolecule targeting unit by the CuAAC reaction, derivative $\mathbf{3 d}$ was designed with an appended alkyne group. The tri-t-butyl 1,4,7,10-tetraazacyclododecane-1,4,7-
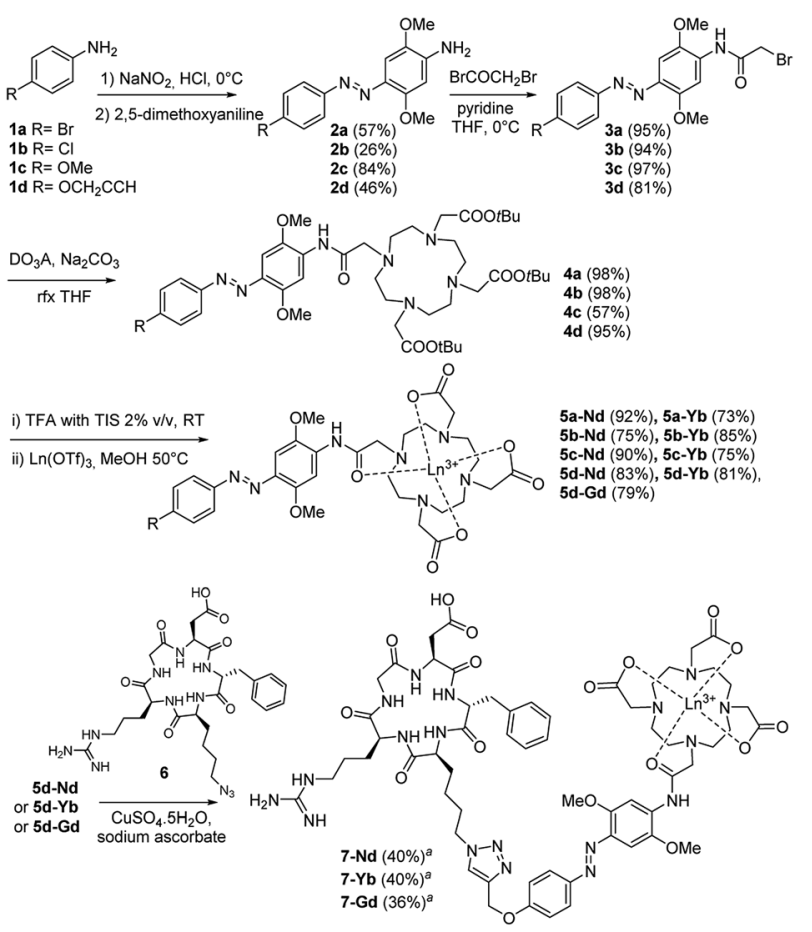

Scheme 1 Synthesis of the 5-Ln and CuAAC reaction between $5 d-L n$ and azido-containing CRGD derivative $6(\mathrm{Ln}=\mathrm{Nd}, \mathrm{Yb}, \mathrm{Gd})$. Percent yields of different reactions are given in parentheses. ${ }^{\text {alsolated yields }}$ after purification by HPLC. triacetate (DO3A-tBu-ester) chelating unit was then anchored to the bromoacetamides 3a-d via a stable amide bond leading to the formation of DO3A ligands $4 a-d$ with high yields. The subsequent deprotection of the $t$-butyl ester groups of $4 \mathbf{4}-$ d using a solution of triisopropylsilane in trifluoroacetic acid $(2 \% \mathrm{v} / \mathrm{v})$ gave the tricarboxylic acids $\mathbf{5 a}-\mathbf{d}$ in good yields. The reaction of $\mathbf{5 a}-\mathbf{d}$ with lanthanide triflates in methanol at $50{ }^{\circ} \mathrm{C}$ resulted in the formation of the corresponding complexes (5-Ln; $\mathrm{Ln}=\mathrm{Gd}, \mathrm{Nd}, \mathrm{Yb})$. Further, the ability of the water-soluble complexes 5d-Ln to act as substrates in CuAAC reactions was investigated with the azido-containing cRGD derivative $6 .^{\mathbf{1 3 - 1 5}}$ Coupling yielded the new and original conjugates 7-Ln $(\mathrm{Ln}=$ $\mathrm{Gd}, \mathrm{Nd}, \mathrm{Yb}$ ). It should be mentioned that metalation was performed before the cycloaddition step to avoid a premature and irreversible sequestering of $\mathrm{Cu}^{2+}$ ions by the carboxylic functionality of the DO3A moiety of $\mathbf{5 d} .^{\mathbf{1 6}}$ This feature is particularly attractive as different bioconjugates could thus be potentially envisaged through the CuAAC reaction. Semi-preparative RPHPLC was then used to purify the 7-Ln complexes. High resolution MS characterization of complexes 7-Nd, 7-Yb, 7-Gd confirmed the formation of the products (see ESI $\dagger$ ).

An extensive photophysical characterization was carried out on aqueous solutions of the 7-Ln conjugates with $\mathrm{Yb}^{3+}, \mathrm{Nd}^{3+}$ and $\mathrm{Gd}^{3+}$ ions. The absorption spectra are depicted in Fig. 1. They reveal that the 7-Ln complexes possess broad absorption bands, almost independent of the nature of the $\mathrm{Ln}^{3+}$ ion, in the UV and visible range up to $550 \mathrm{~nm}$ due to $\pi \leftarrow \pi^{*}$ and $\mathrm{n} \leftarrow \pi^{*}$ transitions with features at $250\left(\varepsilon_{250}=7760 \mathrm{M}^{-1} \mathrm{~cm}^{-1}\right), 280\left(\varepsilon_{280}\right.$ $\left.=4200-4600 \mathrm{M}^{-1} \mathrm{~cm}^{-1}\right), 347\left(\varepsilon_{347}=10250-10400 \mathrm{M}^{-1} \mathrm{~cm}^{-1}\right)$, $405\left(\varepsilon_{405}=12000-12250 \mathrm{M}^{-1} \mathrm{~cm}^{-1}\right)$ and 457 (8900$\left.9300 \mathrm{M}^{-1} \mathrm{~cm}^{-1}\right) \mathrm{nm}$. Azobenzenes are known to undergo cistrans photoisomerization upon illumination. ${ }^{6 b, c, 17}$ Our experiments performed on the solution of the 7-Nd complex demonstrated no significant changes in the shape and intensities of the absorption bands after $2 \mathrm{~h}$ of continuous illumination at $350 \mathrm{~nm}$ (Fig. S1, ESI $\dagger$ ), thus reflecting an absence of photobleaching and photoactivated processes for the studied complexes. The analysis of the ligand-centred emission of the 7Gd complex is useful to gather information about the energy of the triplet state which is hypothesized to play a major role in the energy transfer between the antennae and the $\mathrm{Ln}^{3+}$ ion. ${ }^{3}$ Under excitation in the range $340-450 \mathrm{~nm}$ no emission was observed

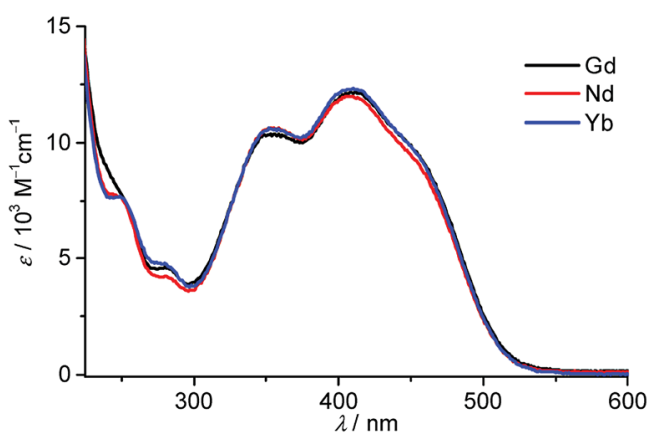

Fig. 1 Absorption spectra of 7-Ln complexes ( $\mathrm{Ln}=\mathrm{Nd}, \mathrm{Gd}, \mathrm{Yb})$ at room temperature $\left(\mathrm{H}_{2} \mathrm{O}, 200 \mu \mathrm{g} \mathrm{mL}^{-1}\right)$. 
for the 7-Gd complex at room temperature. When the temperature was lowered to $77 \mathrm{~K}$ a broad-band emission arising most probably from $\mathrm{n} \rightarrow \pi^{*}$ transitions and centred at $590 \mathrm{~nm}$ was clearly detected under excitation either at 340 or $450 \mathrm{~nm}$ (Fig. 2, red and blue traces). Switching from a continuous to a flash source of excitation $\left(\lambda_{\mathrm{ex}}=340 \mathrm{~nm}\right)$ and applying a delay of 500 $\mu$ s led to the generation of the structured broad-band emission centred at $520 \mathrm{~nm}$, that can be assigned to ${ }^{3} \pi \rightarrow \pi^{*}$ transitions (Fig. 3, black trace). It should be noted that no emission could be detected upon flash excitation at $450 \mathrm{~nm}$. The energy of the ${ }^{3} \pi \pi *$ triplet state, estimated as $0-0$ transition, is thus equal to $20620 \mathrm{~cm}^{-1}(485 \mathrm{~nm})$. The position of the ${ }^{3} \pi \pi^{*}$ triplet state is higher than the accepting levels of $\mathrm{Nd}^{3+}\left({ }^{4} \mathrm{~F}_{3 / 2}\right)$ and $\mathrm{Yb}^{3+}\left({ }^{2} \mathrm{~F}_{5 / 2}\right)$ so can potentially act as a feeding level.

Under excitation in the range of the antenna absorption, sharp emission bands with maxima at 903, 1062 and $1332 \mathrm{~nm}$ that are typical of $\mathrm{Nd}^{3+}$-centred electronic transitions between ${ }^{4} \mathrm{~F}_{3 / 2}$ and ${ }^{4} \mathrm{I}_{J}(J=9 / 2,11 / 2,13 / 2)$ levels as well as a $\mathrm{Yb}^{3+}$-centred band with the maximum at $996 \mathrm{~nm}$ arising from the ${ }^{2} \mathrm{~F}_{5 / 2} \rightarrow{ }^{2} \mathrm{~F}_{7 /}$ ${ }_{2}$ transition were observed for the 7-Nd and 7-Yb complexes, respectively (Fig. 3). Upon monitoring the emission bands of either $\mathrm{Nd}^{3+}$ (at $1064 \mathrm{~nm}$ ) or $\mathrm{Yb}^{3+}$ (at $980 \mathrm{~nm}$ ), the excitation spectra of the 7-Nd and 7-Yb complexes exhibited broad bands in the range $250-550 \mathrm{~nm}$ which are fairly similar to the absorption spectra of the corresponding complexes. These observations indicate that the sensitization of the NIR-emitting $\mathrm{Ln}^{3+}$ ion occurs through the electronic levels of the chromophoric ligand, validating an antenna effect. We can notice the presence of an additional band with a maximum at $582 \mathrm{~nm}$ on the excitation spectrum of 7-Nd. This band can be assigned to ${ }^{4} \mathrm{G}_{5 / 2},{ }^{2} \mathrm{G}_{7 / 2} \leftarrow{ }^{4} \mathrm{I}_{9 / 2}$ transitions of $\mathrm{Nd}^{3+}$ and reflects the possibility of direct excitation of the characteristic emission of this cation through $\mathrm{f}-\mathrm{f}$ transitions. Luminescence lifetimes $\left(\tau_{\mathrm{obs}}\right)$ of $\mathrm{Yb}^{3+}$ and $\mathrm{Nd}^{3+}$-centred transitions were determined in order to monitor changes in the environment around the $\mathrm{Ln}^{3+}$ ion (Table 1). Luminescence decays were collected in $\mathrm{H}_{2} \mathrm{O}$ and $\mathrm{D}_{2} \mathrm{O}$ solutions as the treatment of these data using empirical equations ${ }^{\mathbf{1 8}}$ allows the determination of the number of water molecules coordinated onto $\mathrm{Ln}^{3+}$ ( $q$ values, Table 1 ). In order to establish

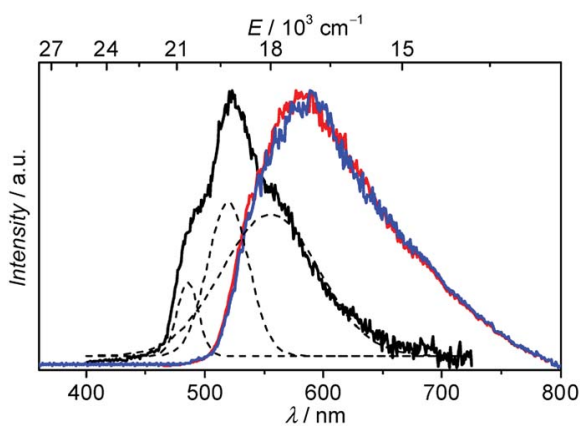

Fig. 2 Emission spectra of the 7-Gd complex recorded at room temperature under continuous excitation at $340 \mathrm{~nm}$ (blue trace) or $450 \mathrm{~nm}$ (red trace), and at $77 \mathrm{~K}$ under excitation at $340 \mathrm{~nm}$ upon applying a $500 \mu$ s delay after the flash (black trace) $\left(\mathrm{H}_{2} \mathrm{O} /\right.$ glycerol $=9 /$ 1, $200 \mu \mathrm{g} \mathrm{mL}^{-1}$ ). The dashed lines represent the Gaussian deconvolution of the phosphorescence spectrum.

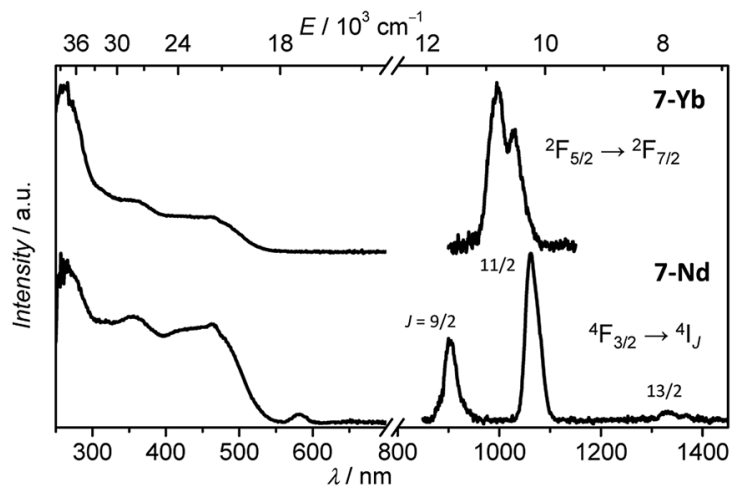

Fig. 3 (Left) Excitation upon monitoring either the $\mathrm{Yb}^{3+}$ emission signal at $980 \mathrm{~nm}$ or $\mathrm{Nd}^{3+}$ at $1064 \mathrm{~nm}$, and (right) emission spectra upon excitation at $450 \mathrm{~nm}$ of 7-Nd and 7-Yb complexes at room temperature $\left(\mathrm{H}_{2} \mathrm{O}, 1 \mathrm{mg} \mathrm{mL}^{-1}\right)$.

whether the presence of the cRGD peptide significantly affected the environment and the protection of the $\mathrm{Ln}^{3+}$ ions, $\tau_{\text {obs }}$ were estimated not only for the 7-Nd, 7-Yb but also for the 5d-Nd, 5dYb (Table S1, ESI $\dagger$ ) complexes. Analysis of the experimental luminescence decays obtained upon excitation in the electronic levels of the organic ligand at $355 \mathrm{~nm}$ and monitoring emissions at 1064 or $980 \mathrm{~nm}$ revealed that they are best fitted with single-exponential functions. The calculated $q$ values for all four complexes are consistent with the presence of one molecule of water coordinated onto $\mathrm{Ln}^{3+}$. In addition, the similarity of the $\tau_{\text {obs }}$ values for $\mathrm{Yb}^{3+}$ and $\mathrm{Nd}^{3+}$ complexes formed with the ligands 5d and 7 demonstrated that the presence of the cRGD peptide had no or a very limited impact on the local environment of $\mathrm{Ln}^{3+}$ ions.

The $\mathrm{Ln}^{3+}$-centred luminescence quantum yield under ligand excitation $\left(Q_{\mathrm{Ln}}^{\mathrm{L}}\right)$ is a quantitative parameter that reflects the efficiency of the antenna to sensitize the NIR-emitting $\mathrm{Ln}^{3+}$ combined with the degree of protection of this cation against sources of non-radiative deactivations. The values of $Q_{\mathrm{Yb}}^{\mathrm{L}}$ and $Q_{\text {Nd }}^{\mathrm{L}}$ can be considered as modest compared with corresponding $\mathrm{Yb}^{3+}$ and $\mathrm{Nd}^{3+}$ DO3A complexes, with one molecule of water coordinated to the $\mathrm{Ln}^{3+}$ ion, while observed lifetime values are similar. ${ }^{19}$ Such results indicate a moderate ability of the studied ligand incorporating an azobenzene chromophore to sensitize $\mathrm{Yb}^{3+}$ and $\mathrm{Nd}^{3+}$.

Table 1 Observed luminescence lifetimes $\left(\tau_{\text {obs }}\right)$ and absolute quantum yields $\left(Q_{\mathrm{Ln}}^{L}\right)$ of 7-Nd and 7-Yb at room temperature $\left(\mathrm{H}_{2} \mathrm{O}\right.$ or $\left.\mathrm{D}_{2} \mathrm{O}, 1 \mathrm{mg} \mathrm{mL}^{-1}\right)^{a}$

\begin{tabular}{|c|c|c|c|c|}
\hline \multirow[b]{2}{*}{ Complex } & \multicolumn{2}{|l|}{$\tau_{\mathrm{obs}}^{b}[\mu \mathrm{s}]$} & \multirow[b]{2}{*}{$q^{c}$} & \multirow[b]{2}{*}{$Q_{\mathrm{Ln}}^{\mathrm{L}{ }^{d}}[\%]$} \\
\hline & $\mathrm{H}_{2} \mathrm{O}$ & $\mathrm{D}_{2} \mathrm{O}$ & & \\
\hline 7-Nd & $0.069(1)$ & $0.238(0)$ & 1.0 & $2.4(1) \times 10^{-4}$ \\
\hline $7-Y \mathbf{b}$ & $0.793(1)$ & $5.843(3)$ & 0.9 & $8.4(1) \times 10^{-5}$ \\
\hline
\end{tabular}

${ }^{a} 2 \sigma$ values in parentheses. Experimental errors: $\tau, \pm 2 \%, Q_{\mathrm{Ln}}^{\mathrm{L}}, \pm 10 \%$. ${ }^{b}$ Under excitation at $355 \mathrm{~nm}$ upon monitoring the emissions of $\mathrm{Nd}^{3+}$ at $1064 \mathrm{~nm}$ and $\mathrm{Yb}^{3+}$ at $980 \mathrm{~nm}$. ${ }^{c}$ Calculated according to phenomenological equations reported in ref. $17 .{ }^{d}$ Under excitation at $450 \mathrm{~nm}$. 
In summary, we have described the construction of an original system that combines azobenzene-based chromophores with the cyclen coordinating unit and the targeting cRGD peptide moiety in five easy-to-perform and versatile steps. This strategy could find widespread application by anchoring Ln(III)-based luminescent probes to diverse biomolecules or targeting units. ${ }^{20}$ Photophysical studies demonstrated that this system allows the sensitization of both NIR-emitting $\mathrm{Nd}^{3+}$ and $\mathrm{Yb}^{3+}$ ions in aqueous solutions although with moderate efficiency. The analysis of the luminescence lifetimes confirmed the presence of a water molecule coordinated onto $\mathrm{Ln}^{3+}$ which causes non-radiative deactivation and partially explains the relatively modest values of NIR quantum yields. Nevertheless, the versatility of the described approach that allows: (i) a variation of substituents on the chromophoric unit in order to enhance the sensitization efficiency of NIR-emitting $\mathrm{Ln}^{3+}$ ion or to replace a water molecule from the $\mathrm{Ln}^{3+}$ coordination sphere, (ii) an exchange of the cyclen coordination unit to the one with higher denticity, would address current limitations and open promising possibilities for practical applications of these molecules.

\section{Conflicts of interest}

There are no conflicts to declare.

\section{Acknowledgements}

M. C. B. thanks the Association pour la Recherche sur le Cancer (ARC), the Region Centre-Val de Loire (APR-IR 2011 Multiplex) and the LABEX SynOrg (ANR-11-LABX-0029) for financial support. S. V. E. was supported through a grant from the European Community's Seventh Framework Programme (FP7 IEF Dendrimage - project number 316906). S. P. acknowledges support from the Institut National de la Santé et de la Recherche Médicale (INSERM). Dr M. Galibert is greatly acknowledged for his help with the peptide conjugation reactions. We acknowledge Dr G. Gabant and the mass spectrometry platform of CBM for the MS analyses of peptides and peptide conjugates.

\section{Notes and references}

1 (a) R. Weissleder and V. Ntziachristos, Nat. Med., 2003, 9, 123; (b) J. V. Frangioni, Curr. Opin. Chem. Biol., 2003, 7, 626; (c) I. Martinić, S. V. Eliseeva and S. Petoud, J. Lumin., 2017, 189, 19.

2 (a) S. V. Eliseeva and J.-C. G. Bünzli, Chem. Soc. Rev., 2010, 39, 189; (b) J.-C. G. Bünzli, Chem. Rev., 2010, 110, 2729.

3 (a) H. Uh and S. Petoud, C. R. Chim., 2010, 13, 668; (b) J.-C. G. Bünzli and S. V. Eliseeva, Photophysics of Lanthanoide Coordination Compounds, in Comprehensive Inorganic Chemistry II, ed. J. Reedijk, K. Poeppelmeier Elsevier B.V., Amsterdam, 2013, vol. 8, ch. 8.08, pp. 339-398.

4 (a) A. Foucault-Collet, K. A. Gogick, K. A. White, S. Villette, A. Pallier, G. Collet, C. Kieda, T. Li, S. J. Geib, N. L. Rosi and S. Petoud, Proc. Natl. Acad. Sci. U. S. A., 2013, 110, 17199; (b) A. Foucault-Collet, C. M. Shade, I. Nazarenko,
S. Petoud and S. V. Eliseeva, Angew. Chem., Int. Ed., 2014, 53, 2927; (c) I. Martinić, S. V. Eliseeva, T. N. Nguyen, V. L. Pecoraro and S. Petoud, J. Am. Chem. Soc., 2017, 139, 8388; (d) I. Martinić, S. V. Eliseeva, T. N. Nguyen, V. L. Pecoraro and S. Petoud, Chem. Sci., 2017, 8, 6042.

5 S. L. Wu and W. D. Horrocks, J. Chem. Soc., Dalton Trans., 1997, 1497.

6 (a) F. Hamon, F. Djedaini-Pilard, F. Barbot and C. Len, Tetrahedron, 2009, 65, 10105; (b) J. Griffiths, Chem. Soc. Rev., 1972, 1, 481; (c) A. A. Beharry and G. A. Woolley, Chem. Soc. Rev., 2011, 40, 4422; (d) M. P. Placidi, A. J. L. Villaraza, L. S. Natrajan, D. Sykes, A. M. Kenwright and S. Faulkner, J. Am. Chem. Soc., 2009, 131, 9916; (e) K. Aita, T. Temma, Y. Kuge, K. Seki and H. Saji, Luminescence, 2010, 25, 19.

7 (a) C. W. Tornøe, C. Christensen and M. Meldal, J. Org. Chem., 2002, 67, 3057; (b) V. V. Rostovtsev, L. G. Green, V. V. Fokin and K. B. Sharpless, Angew. Chem., Int. Ed., 2002, 41, 2596; (c) F. de Moliner, N. Kielland, R. Lavilla and M. Vendrell, Angew. Chem., Int. Ed., 2017, 56, 3758.

8 (a) R. O. Hynes, Cell, 1992, 69, 11; (b) G. J. Mizejewski, Proc. Soc. Exp. Biol. Med., 1999, 222, 124; (c) H. Jin and J. Varner, Br. J. Cancer, 2004, 90, 561.

9 (a) M. Gurrath, G. Müller, H. Kessler, M. Aumailley and R. Timpl, Eur. J. Biochem., 1992, 210, 911; (b) D. Arosio and C. Casagrande, Adv. Drug Delivery Rev., 2016, 97, 111.

10 (a) F. Danhier, A. Le Breton and V. Préat, Mol. Pharm., 2012, 9, 2961; (b) K. Temming, R. M. Schiffelers, G. Molema and R. J. Kok, Drug Resist. Updates, 2005, 8, 381.

11 (a) J. Hedouin, C. Schneider, I. Gillaizeau and C. Hoarau, Org. Lett., 2018, 20, 6027; (b) N. Gigant, L. ChaussetBoissarie and I. Gillaizeau, Chem. -Eur. J., 2014, 20, 7548.

12 K.-P. Tseng, Y.-T. Tsai, C.-C. Wu, J.-J. Shyue, D. M. Bassani and K.-T. Wong, Chem. Commun., 2013, 49, 11536.

136 is a well-established cRGD derivative for conjugation with imaging probes, see for example: (a) I. Dijkgraaf, A. Y. Rijnders, A. Soede, A. C. Dechesne, G. Wilma van Esse, A. J. Brouwer, F. H. M. Corstens, O. C. Boerman, D. T. S. Rijkersa Rob and M. J. Liskamp, Org. Biomol. Chem., 2007, 5, 935; (b) S. S. van Berkel, A. J. Dirks, S. A. Meeuwissen, D. L. L. Pingen, O. C. Boerman, P. Laverman, F. L. van Delft, J. J. L. M. Cornelissen and F. P. J. T. Rutjes, ChemBioChem, 2008, 9, 1805; (c) J. Paleček, G. Dräger and A. Kirschning, Synthesis, 2011, 653; (d) P. Verwilst, S. V. Eliseeva, L. Vander Elst, C. Burtea, S. Laurent, S. Petoud, R. N. Muller, T. N. ParacVogt and W. M. De Borggraeve, Inorg. Chem., 2012, 51, 6405; (e) H. Li, H. Zhou, S. Krieger, J. J. Parry, J. J. Whittenberg, A. V. Desai, B. E. Rogers, P. J. A. Kenis and D. E. Reichert, Bioconjugate Chem., 2014, 25, 761; $(f)$ P. Verwilst, S. V. Eliseeva, S. Carron, L. Vander Elst, C. Burtea, G. Dehaen, S. Laurent, K. Binnemans, R. N. Muller, T. N. Parac-Vogt and W. M. De Borggraeve, Eur. J. Inorg. Chem., 2011, 2011, 3577.

14 For other azide-containing cRGD derivatives, see for example: (a) C. Wängler, S. Maschauer, O. Prante, M. Schäfer, R. Schirrmacher, P. Bartenstein, M. Eisenhut 
and B. Wängler, ChemBioChem, 2010, 11, 2168; (b) M. Galibert, O. Renaudet, P. Dumy and D. Boturyn, Angew. Chem., Int. Ed., 2011, 50, 1901.

15 A novel synthetic approach towards azidocylopeptide 6 was optimized and is based on a convenient solid-phase cyclization adapted to further scale up, see the ESI $\uparrow$ for details.

16 (a) S. V. Smith, J. Inorg. Biochem., 2004, 98, 1874; (b) Y. Song, E. K. Kohlmeir and T. J. Meade, J. Am. Chem. Soc., 2008, 130, 6662.

17 A stable trans $(E)$ configuration for azobenzene-based compounds $\mathbf{2 a - d}$ is assumed. See: (a) K.-P. Tseng, Y.-T. Tsai, C.-C. Wu, J.-J. Shyue, D. M. Bassani and K.-T. Wong, Chem. Commun., 2013, 49, 11536; (b) J. Zeitouny, C. Aurisicchio, D. Bonifazi, R. De Zorzi, S. Geremia, M. Bonini, C.-A. Palma, P. Samorì, A. Listorti,
A. Belbakrab and N. Armaroli, J. Mater. Chem., 2009, 19, 4715; (c) E. Vaselli, C. Fedele, S. Cavalli and P. A. Netti, ChemPlusChem, 2015, 80, 1547.

18 (a) A. Beeby, S. Faulkner, D. Parker and J. A. G. Williams, J. Chem. Soc., Perkin Trans. 1, 2001, 2, 1268; (b) S. Faulkner, A. Beeby, M.-C. Carrié, A. Dadabhoy, A. M. Kenwright and P. G. Sammes, Inorg. Chem. Commun., 2001, 4, 187.

19 (a) Z. Hashami, A. F. Martins, A. M. Funk, V. C. Jordan, S. Petoud, S. V. Eliseeva and Z. Kovacs, Eur. J. Inorg. Chem., 2017, 43, 4965; (b) M. Isaac, L. Raibault, C. Cepeda, A. Roux, D. Boturyn, S. V. Eliseeva, S. Petou and O. Sénèque, Chem. -Eur. J., 2017, 23, 10992.

20 (a) A. J. Amoroso and S. J. A. Pope, Chem. Soc. Rev., 2015, 44, 4723; (b) R. D. Teo, J. Termini and H. B. Gray, J. Med. Chem., 2016, 59, 6012 . 